\title{
A RELAÇÃO ENTRE EDUCAÇÃO E LINGUAGEM E A PRODUÇÃO DO CONHECIMENTO
}

\section{Educación y Lenguaje sus Relaciones y la Producción del Conocimiento}

Jayme Ferreira Bueno ${ }^{1}$

\section{Resumo}

Este artigo, que pode ser dividido em duas partes, procura primeiro relacionar a linguagem e a educação e, em seguida, o texto literánio com as atividades pedagógicas, na busca da produção do conhecimento no ensino superior e em programa de pós-graduação nas áreas da Educação e de Letras. O estudo enfoca em especial um poema da literatura portuguesa, que, por suas caractenísticas, integra-se ao espírito da sala de aula por tratar-se de uma "lição" poética, mas que encerra também outras lições. É um texto de um poeta-professor, António Gedeão, pseudônimo do professor-poeta Rômulo de Carvalho, que nos fala com a voz da emoção, própria da poesia, mas que nos transmite conhecimentos numa linguagem poética que soube incorporar a ela a linguagem do domínio da ciência.

Palavras-chave: Educação; Educação e linguagem; Educação e literatura; Educação e poesia; Linguagem científica e linguagem poética; Saberes; Produção do conhecimento.

1 Doutor em Letras pela USP, professor de Literatura Portuguesa e Professor-Orientador do Programa de Pós-Graduação em Educação da Pontifícia Universidade Católica do Paraná PUCPR. Rua Cláudio Chatagnier, 287 - 82520-590 - CURITIBA - PR

E-mail: rjbueno@qwnet.com.br 


\section{Resumen}

Este artículo, que se puede dividir en dos partes, procura relacionar el lenguaje y la educación y, de forma más específica, hacer relaciones del texto literario con las actividades pedagógicas, en la búsqueda de la producción del conocimiento en la enseñanza de grado superior y en programas de postgrado en las áreas de la Educación y de las Letras. El estudio enfoca en especial un poema de la literatura portuguesa, que, por sus características, se integra al espíritu de la sala de aula por tratarse de una "lección" poética, pero que contiene en sí también otras lecciones. Es un texto de un poeta-profesor, António Gedeão, seudónimo del profesor-poeta Rómulo de Carvalho, que nos habla con la voz de la emoción, propia de la poesía, pero que también nos transmite conocimientos en el lenguaje poético que ha sabido incorporar a ella el lenguaje del ámbito de la ciencia.

Palabras-clave: Educación; Educación y lenguaje; Educación y literatura; Educación y poesía; Lenguaje científico y lenguaje poético; Saberes; Producción del conocimiento.

\section{Introdução}

Hoje, quando vivemos novos tempos no modo de ver e de enfocar as diversas áreas do conhecimento, é comum ouvir-se falar de relação entre educação e linguagem, educação e literatura. $O$ que, porém, não nos parece tão fácil é falar desse tema. Como tudo que envolve interdisciplinaridade, multidisciplinaridade e transdisciplinaridade, conceitos que surgem, transformam-se, ou mesmo desaparecem, e por isso intrincados e complexos, a aproximação entre educação e linguagem e, mais especificamente, entre educação e literatura, também se apresenta com esse mesmo grau de dificuldade.

Como sabemos pela própria história da educação, não foi sempre assim quanto a se falar do relacionamento entre os diferentes saberes. Cada área, ou cada disciplina, restringia-se ao seu próprio objeto de estudo, numa forma de fechamento em si mesma. O pensamento mudou, mudaram os paradigmas, porque mudou o mundo. As relações das pessoas e das organizações na sociedade agora são outras, diferentes de como eram. Vivemos, segundo dizem, a era da informação, a "Sociedade do Conhecimento".

Esse movimento dialético de transformações, porém, é de todos os tempos. Na literatura, os autores do Renascimento já poetizavam a mudança do mundo, embora, para conferir poeticidade ao tema, consideravam que não mudava o que eles gostariam que mudasse: 0 sofrimento, a inconstância do amor, etc.

Vejam-se, como exemplos, estes versos de Camões (1980, v. 2, p. 
Mudam-se os tempos, mudam-se as vontades,

Muda-se o ser, muda-se a confiança:

Todo o mundo é composto de mudança,

Tomando sempre novas qualidades.

(...)

E, afora este mudar-se cada dia,

Outra mudança faz de mor espanto,

Que não se muda já como soía.

No Programa de Pós-Graduação em Educação da Pontifícia Universidade Católica do Paraná, na Linha de Pesquisa Teoria e Prática Pedagógica da Educação Supenior, reservou-se, acertadamente, dentre os estudos de diferentes Saberes, um espaço para Educação e Linguagem. Nesse recinto, se não virtual, ao menos conceitual, formou-se o Grupo de Pesquisa Educação, Linguagem e Produção do Conhecimento, que tem sido origem e sustentação de algumas pesquisas nas áreas da educação, mas com foco na linguagem. São estudos sobre o ensino da língua portuguesa ou de línguas estrangeiras nos cursos de graduação de Letras, ou, ainda, sobre a presença do texto literário, ou especificamente do texto poético, como elemento condutor de atividades em sala de aula nesses mesmos cursos ou em cursos de Pedagogia. Outros estudos enfocam a função da leitura na escola. Outros, finalmente, vêem as artes de um modo geral - diferentes linguagens que são como recursos pedagógicos.

Este artigo quer inserir-se nesse ambiente de intercomunicação entre saberes, participar da discussão do ensino e da aprendizagem da literatura. Enfim, é objetivo integrar-se ao estudo da problemática referente à relação entre educação, linguagem e produção do conhecimento.

Quanto à sua apresentação, o presente estudo pode dividir-se em duas partes. Na primeira, colocam-se alguns aspectos da relação entre educação e linguagem, ou entre linguagem e educação, na dependência de essa relação ser vista da perspectiva de teóricos da educação ou sob o enfoque de lingüistas. Na segunda parte, apresenta-se a temática em um poema que inter-relaciona linguagem comumente tratada como científica com outra dita poética.

A poesia moderna, ou aquela surgida após os movimentos de vanguarda do Modernismo, pode nos proporcionar, com mais propriedade, esse tipo de achega, o que resulta num "estranhamento"2 para usar o termo cunhado pelos formalistas russos. (CHKLOVSKI, apud EIKHENBAUM, 1976, p. 39-

2 O termo e, conseqüentemente, o conceito estranhamento aparece, em algumas traduções como singularização. Segundo Eco (1968, p. 123), "o estranhamento era para Sklovsky um desviar da norma, um golpear o leitor com um artifício contrário a seus sistemas de expectativas e capaz de fixar sua atenção sobre o elemento poético que lhe era proposto". Pode-se conferir com Chklovski (1976). 
56). Segundo esses teóricos, era o estranhamento, causado por certo tipo de linguagem, ou, como em alguns casos, pela combinação de linguagens, o que caracterizava a literariedade, ou seja, o ser literário de um texto. No caso que se irá tratar é a aproximação ou a convivência de uma linguagem da área das ciências com outra mais conhecida em textos literários ou, especificamente, na poesia.

\section{Educação e linguagem}

Barthes, na introdução de Elementos de semiologia, como fizeram os semiologistas e lingüistas de todos os tempos, enfatiza a importância da linguagem na "tradução" de todos os "objetos, imagens, comportamentos", porque, segundo ele, "qualquer sistema semiológico repassa-se de linguagem". É mais enfático ainda quando afirma: "o mundo dos significados não é outro senão o da linguagem" (BARTHES, 1977, p. 12). Hoje, quase um século após Saussure, pai da lingüística moderna, e mais de quarenta depois do estruturalismo francês, são compreensíveis tais afirmações. O mesmo, porém, não acontecia em tempos que antecederam essas épocas, quando os estudos lingüísticos se guiavam por orientações historicistas e evolucionistas dos denominados neogramáticos do século XIX (DUBOIS et al., 1978; LYONS, 1979).

Wittgenstein, com toda sua complexidade, parece tornar-se claro quando afirma que "o homem possui a capacidade de construir linguagens com as quais se pode exprimir todo sentido". Porém, ao menos para mim, volta a ser altamente complexo ao escrever: "Toda filosofia é 'crítica da linguagem'” (WITTGENSTEIN, 1994, p. 165). Em ambos os casos, contudo, ele ressalta a importância da linguagem. No primeiro, reforça-se a idéia de que os sentidos, ou seja, os significados, no dizer de Barthes, são traduzidos, expressos, transmitidos e construídos pela linguagem; no segundo, parece tratar-se do fato de a linguagem fundamentar toda a filosofia. E a filosofia se fazendo na linguagem e com a linguagem, se esta interpretação estiver correta.

De um modo geral, os autores, mesmo ao criticar os lingüistas, preocupam-se com a linguagem como meio de comunicação e, também, do aprender, do construir e do receber e transmitir o conhecimento. É o caso, por exemplo, de Bakhtin (1981, p. 106), que, ao procurar explicar pela dialética marxista o sentido da palavra, afirma: "Quando o filólogo-lingüista alinha os contextos possíveis de uma palavra dada, ele acentua o fator de conformidade à norma; o que lhe importa é extrair desses contextos dispostos lado a lado uma determinação descontextualizada, para poder encerrar a palavra num dicionánio". Logo adiante, no seu texto, o mesmo autor declara: "Os indivíduos não recebem a língua pronta para ser usada; eles penetram na corrente da comunicação verbal; ou melhor, 
somente quando mergulham nessa corrente é que começam a operar". Tudo isso fica mais claro quando ele reitera e amplia o campo do seu entendimento de língua, atribuindo à linguagem importância fundamental: "Os sujeitos não 'adquirem' sua língua materna; é nela e por meio dela que ocorre o primeiro despertar da consciência” (BAKHTIN, 1981, p. 108). É a língua, ele fala de língua matema em oposição à língua estrangeira, que forma a consciência, o próprio indivíduo, porém num ambiente de interação pelo produto da fala - a enunciação. Nas palavras do próprio Bakhtin (p. 109), "A enunciação é de natureza social".

Sabemos todos da importância que tiveram os estudos de Vigotski ${ }^{3}$ para a educação. A teoria construtivista promoveu mudanças na escola, nos currículos, na forma de ensinar e, principalmente, contribuiu para o surgimento de novos paradigmas na educação. O construtivismo de Vigotski e de seus seguidores - Luria, por exemplo -, ao lado de outras teorias como o interacionismo de Piaget, alterou profundamente o modo de ver todo o processo do ensino e da aprendizagem (POZO, 2002; UCHÔA, 2005; CAMPOS, 2005).

Ao tratar da comunicação, uma das funções da linguagem e fundamental para a educação, Vigotski (2003, p. 7), após criticar teorias lingüísticas que se apoiavam apenas na idéia do signo (a palavra ou o som) como meio de comunicação, afirma: "um estudo mais profundo do desenvolvimento da compreensão e da comunicação na infância levou à conclusão de que a verdadeira comunicação requer significado - isto é generalização -, tanto quanto signos." O conceito de generalização, ao lado do conceito de simplificação, Vitgoski aproveita, conforme sua própria declaração, do lingüista norte-americano Edward Sapir ${ }^{4}$. Segundo esse autor, nas palavras de Vigotski, "o mundo da experiência precisa ser extremamente simplificado e generalizado antes que possa ser traduzido em símbolos" (VIGOTSKI, 2003, p. 7).

Dessa forma, Vigotski (2003, p. 7-8) pôde concluir seu raciocínio:

Somente assim a comunicação toma-se, de fato, possível, pois a experiência do indivíduo encontra-se apenas em sua própria consciência e é, estritamente falando, comunicável. Para se tomar comunicável, deve ser incluída numa deteminada categoria que, por convenção tácita, a sociedade humana considera uma unidade. Assim, a verdadeira comunicação humana pressupõe uma atitude generalizante, que constitui um estágio avançado do desenvolvimento do significado da palavra. As formas mais elevadas da comunicação humana somente são possíveis porque o pensamento do homem reflete uma realidade conceitualizada.

3 Na redação do texto, para efeito de uniformização da grafia do nome do estudioso russo, adotei a forma Vigotski, mais próxima da língua portuguesa. No entanto, quando se tratar de citação ou de título de livros ou artigos, aparecerão outras, como Vygotsky, Vigotskii.

4 Edward Sapir (1884-1939), antropólogo e lingüista, nasceu na Alemanha, mas radicou-se nos Estados Unidos, onde, ao lado de Bloomfield, liderou o estruturalismo norte-americano, com base no estudo e descrição de línguas indígenas. 
No campo mais específico da relação entre linguagem e educação, Rondal (1980, p. 73) declara: "La escuela (...) tiene por objeto el explicitar y elaborar por el lenguaje los principios y las operaciones que se aplican a los objetos (ciencias) y a las personas (humanidades)" ${ }^{5}$. Pela afirmação desse psicolingüista, pode-se perceber a importância que a linguagem assume para a escola, e, conseqüentemente, para a educação, no fazer científico e no formar 0 cidadão.

Concluindo este tópico, reitera-se o reconhecimento pelo que a linguagem representa e pelo papel que desempenha na construção e na comunicação do conhecimento na escola ou em outra instância em que se ensino e se aprenda. Pedagogos, lingüistas, psicolingüistas, educadores de um modo geral dedicam-se ao tema e contribuem com pesquisas, estudos, propostas para o fortalecimento da relação que há entre linguagem e educação.

\section{Educação, literatura e construção do conhecimento: uma problematização}

O que se disse sobre a relação entre educação e linguagem poderia se repetir no enfoque deste item, por se tratar a literatura de um produto da linguagem. Porém, como certa especificidade da linguagem, o texto poético apresenta características que lhe são próprias e que podem ser enfocadas de modo específico. É o que se busca fazer nesta parte do estudo.

O problema com que se depara é de como a literatura tem freqüentado, ao menos teoricamente, a sala de aula e que contribuição ela pode trazer para o ensino e para aprendizagem nos diferentes ramos do saber, mas especialmente nas áreas da Educação e de Letras.

Sabe-se por alguns estudos, principalmente dos programas de pósgraduação, que o texto literário, ao lado de textos de outros gêneros, vem aparecendo com bastante freqüência, e não só nos cursos das duas áreas referidas, mas em diversas outras. Muitas vezes, tem a função apenas de ilustração, com frases de autores mais popularizados - não populares - como Fernando Pessoa, Guimarães Rosa, ou letras de compositores famosos. Chico Buarque talvez seja o exemplo mais claro dessa tendência.

Tratando da problemática de se trabalhar com o texto em sala de aula, há diversos trabalhos de mestrado defendidos no Programa de Pós-Gra-

5 Numa tradução livre e com algum acréscimo interpretativo, "A escola (...) tem por objetivo esclarecer e formular pela linguagem os princípios e as operações que se aplicam aos objetos (no caso das ciências, as ditas exatas, naturais) e às pessoas (quando se trata das ciências humanas)." 
duação em Educação da PUCPR. Cito alguns como exemplos, dentre aqueles dos quais tive a oportunidade de participar como professor-orientador:

1. - - A leitura e o ensino com pesquisa no curso superior: uma proposta de aprender a aprender, de Ilze Salete Chiarello, dissertação defendida em 2000. No estudo, aponta-se a leitura do texto, incluindo-se o texto literário e, particularmente, o texto poético, como elemento fundamental para o ensino com pesquisa e para a formação crítica, reflexiva e criativa;

2.․ - Arte-educação na produção de texto crítico e criativo no ensino superior, de Luciana Bracarense Costa Fernandez, trabalho aprovado em 2001. Nele, defende-se a produção de texto crítico e criativo e, portanto, enfocando o pensamento e o sentimento. Para a criticidade, apóia-se na coerência, coesão e na reflexão sobre a realidade. Para a criatividade, fundamenta-se principalmente na metáfora, base do texto poético;

3.․ - A prática pedagógica inovadora e a poesia como um elemento articulador no ensino da língua portuguesa no curso de Pedagogia, de Ivana Aparecida Costa Cavalcanti, dissertação defendida em 2001. O trabalho busca solidificar a idéia de que com a poesia se constroem conhecimentos em língua portuguesa com mais eficiência e criticidade (BUENO, 2001).

Esses trabalhos, resultantes de pesquisas levadas a efeito pelos mestrandos, foram orientados e desenvolvidos dentro da Linha de Pesquisa Teoria e Prática Pedagógica da Educação Superior, no Núcleo de Estudos Saberes: Linguagem e Educação do Programa de Pós-Graduação já referido. Eles se inscrevem no contexto da produção do conhecimento na área da educação, mas têm como apoio o conhecimento e o estudo de disciplinas relacionadas com a linguagem, como é a proposta deste artigo.

\section{Um poema, uma lição}

O poema "Lição sobre a água", que será enfocado a seguir, é de autoria do poeta português António Gedeão, pseudônimo de Rômulo de Carvalho (1906-1997). Licenciado em Ciências Físico-Químicas e em Ciências Pedagógicas, Rômulo de Carvalho, como professor de Ciências Físico-Químicas, lecionou no Liceu Camões, em Lisboa, no Liceu D. João III, em Coimbra e, posteriormente, no Liceu Pedro Nunes, em Lisboa. Exerceu intensa atividade na área científica e foi co-director da Gazeta de Física da Faculdade de Ciências de Lisboa, cargo que exerceu de 1946 até 1974. Como historiador da Ciência, escreveu obras como História do Telefone, o primeiro de uma lista de livros didáticos, na qual conta a história não só do telefone, como indica 0 título, mas também da fotografia, dos balões, da eletricidade estática, do átomo, da radioatividade, dos isótopos e da energia nuclear e História do Gabi- 
nete de Física da Universidade de Coimbra, entre outras. Publicou inúmeros livros didáticos, como, por exemplo, Compêndio de Química para o 3. Ciclo.

Como poeta, seu primeiro livro somente saiu publicado em 1956, embora desde a infância demonstrasse tendências literárias, que foram deixadas de lado até a maturidade, pelo envolvimento com a ciência e com 0 magistério. Foi nessa obra, Movimento perpétuo, que surge o pseudônimo Antônio Gedeão. Dois anos após, em 1958, aparece novo livro de poemas, Teatro do mundo. Transcorreram mais três anos para aparecer o novo livro, Máquina de fogo. Em 1967, lança Linhas de força, que, no ano seguinte, é incorporado aos outros três sobre o título Poesias completas: 1956-1957.

Na literatura, publicou ainda uma peça de teatro, RTX 78/24, em 1963, e uma coletânea de contos, A poltrona e outras novelas, de 1973. Publicou também poemas de circunstâncias em datas histórias, como Poema para Galileo, em 1964, nas comemorações do quarto centenário do nascimento de Galileu Galilei (1564-1642). Esse poema, mais tarde, foi incluído na obra Linhas de força, de 1967.

Novamente, sua produção poética e literária é prejudicada pelas várias atividades científicas e culturais em cargos que passou a ocupar e, também, pela publicação de inúmeras outras obras de caráter científico e pedagógico. Embora não tivesse produzido obra literária, nem especificamente poética, de grande fôlego depois de 1968, nunca deixou de publicar poemas em revistas e jornais literários de Portugal. A sua marca na literatura, na ciência quer como professor, quer como divulgador - e na cultura portuguesa são inegáveis. Foi uma vida de 91 anos voltada para a profissão de ensinar, que a exerceu como verdadeira missão. Sua participação nos diversos campos do saber foi importante contribuição para o desenvolvimento da ciência em seu país. A ciência e Portugal, sua terra - recantos, gente, profissões e costumes , tudo está sempre presente na sua obra.

\section{LCCÃO SOBRE A ÁGUA}

Antônio Gedeão

Este líquido é água.

Quando pura

é inodora, insípida e incolor.

Reduzida a vapor,

Sob tensão e a alta temperatura,

Move os êmbolos das máquinas que, por isso,

Se denominam máquinas de vapor. 
É um bom dissolvente.

Embora com exceções mas de um modo geral,

dissolve tudo bem, ácidos, bases e sais.

Congela a zero graus centesimais

E ferve a 100, quando à pressão normal.

Foi neste líquido que numa noite cálida de Verão,

sob um luar gomosos e branco de camélia,

apareceu a boiar o cadáver de Ofélia

com um nenúfar na mão.

(GEDEÃO, 1975, p. 244-5.)

Este poema faz parte do livro Linhas de força, publicado inicialmente em 1967 e, posteriormente, incluído em Poesias completas, de 1968. Linhas de força é considerado pela crítica a obra poética mais significativa do autor. Sena (1968, p. 76), no estudo introdutónio de Poesias completas, declara: "Tomara muitos publicar um livro como este, é óbvio. E alguns dos poemas dele são por certo dos melhores de António Gedeão”. Referindo-se especificamente ao poema que está sendo enfocado, e fazendo menção ao perfeito equilíbrio entre diferentes tipos de linguagens, o mesmo autor afirma: "No terceiro dos livros, em dois poemas a síntese era perfeita entre a terminologia

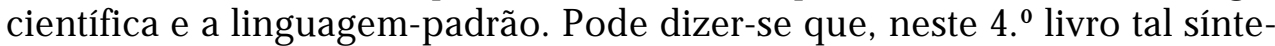
se só se verifica - aliás admiravelmente - num poema (Lição sobre a água)" (SENA, 1968, p. 74).

Em trabalho anterior na área da Teoria da Literatura, nos anos setenta, ainda sob influência do estruturalismo, tive a oportunidade de estudar este poema do ponto de vista do procedimento poético. Nesse estudo, discutia-se a postura científica, e o poema "Lição sobre a água" era apontado como específico da poética de Antônio Gedeão, exatamente por se verificar nele, de acordo com a análise já referida de Sena (1968, p. 74), a síntese entre a terminologia científica e a linguagem-padrão (BUENO, 1979).

Depois desse trabalho, vários outros autores surgiram com estudos sobre "Lição sobre a água". É o caso, por exemplo, de Fiorin e Savioli (2002, p. 115-117), que analisam o poema do ponto de vista da denotação e da conotação, de forma coincidente com a natureza do trabalho que defendi como dissertação de mestrado e do qual existe exemplar depositado na Biblioteca da Universidade de São Paulo.

Iniciando o enfoque do poema pelo título, podem-se deduzir daí duas "lições". Uma sobre o elemento água, com suas propriedades, o que reflete um posicionamento científico; e uma outra "lição" que se mostra 
sobre a água, ou seja, em cima da água, boiando sobre ela, de caráter mais subjetivo e que busca a poeticidade.

Na introdução do poema - as duas primeiras estrofes - são expostas em forma de lição, as características da água, numa descrição muito próxima daquela que é comum aparecer em textos de livros científicos. Aí estão presentes as qualidades físico-químicas da água. Há, portanto, uma identificação com o denominado discurso científico. É um texto descritivo, em oposição à segunda parte, claramente uma opção pelo texto narrativo. Como gênero descritivo, os verbos se encontram no presente, em contraste com as formas verbais da segunda parte, que estão no passado. É o que se denominava discurso objetivo, aquele cujo sujeito seria a própria ciência e não um sujeito da enunciação, numa visão estruturalista, como de Greimas (1976).

Essa semelhança se ressalta no momento em que se comparam as duas primeiras estrofes do poema com fragmentos de um texto de uma enciclopédia ${ }^{6}$ :

Este líquido é água.

Quando pura

é inodora, insípida e incolor.

Reduzida a vapor,

Sob tensão e a alta temperatura,

Move os êmbolos das máquinas que, por isso,

Se denominam máquinas de vapor.

É um bom dissolvente.

Embora com exceções mas de um modo geral, dissolve tudo bem, ácidos, bases e sais.

Congela a zero graus centesimais

E ferve a 100, quando à pressão normal. (GEDEÃO, 1975)

A água pura é um líquido inodoro, insípido, transparente e quase incolor. (...) Suas propriedades físicas são usadas para a definição de muitas constantes físicas. Funde-se a 100,000ํㅡㄹ cob pressão de $760 \mathrm{~mm} \mathrm{Hg.} \mathrm{(...)} \mathrm{Tem} \mathrm{grande}$ capacidade calorífica; a 14,5을 $\mathrm{C}$, seu poder calorífico é de 1,000 caloria. (...) Reage com os óxidos básicos, formando bases; e com os óxidos ácidos, formando ácidos. Decompõe diversas substâncias, pela reação de hidrólise. Toma parte na constituição de muitos compostos, principalmente sais, formando os hidratos.

(ENCICLOPÉDIA BRASILEIRA MÉRITO, s.d.)

6 O texto foi transcrito da Enciclopédia Brasileira Mérito, v. 1, p. 306-310. 
O diálogo entre os dois textos é facilmente constatado, o que nos mostra certa "postura científica" no texto poético de António Gedeão. Essa postura científica, como procedimento, ou com figura poética, apresenta-se de dois modos: primeiramente, pela descrição de um fazer científico - o descrever a água - e pela contraposição de um discurso aparentemente científico a um discurso consagrado tradicionalmente como poético.

Passando para a segunda parte do poema - a terceira estrofe -, observa-se que também traz em si uma "lição", porém de caráter mais subjetivo, e agora não mais num tom de ciência, mas num estilo de aviso, de advertência, próprio dos ensinamentos. É como se chamasse a atenção para o perigo da água ou, então, o perigo da água como local e instrumento de suicídio, como, comentando o poema, interpretou Mattos (s.d.), com apoio em Braga ${ }^{7}$. Formalmente, apresenta-se de modo diferente, com nova técnica na construção do texto. Recordando a estrofe, ela é a seguinte:

Foi neste líquido que numa noite cálida de Verão, sob um luar gomosos e branco de camélia, apareceu a boiar o cadáver de Ofélia com um nenúfar na mão.

(GEDEÃO, 1975)

Aqui, como já se mencionou, o gênero é narrativo. As formas verbais - Foi e apareceu - denotam um tempo que passou, característica de tal gênero textual. Como na primeira parte, que se relacionava a um outro texto, o mesmo acontece com esta segunda parte do poema. Agora, a intertextualidade se dá não mais com um texto proveniente da ciência, mas da literatura, mais precisamente com um trecho da peça Hamlet, de Shakespeare:

Ao tentar pendurar suas coroas nos galhos inclinados, um dos ramos invejosos quebrou, lançando na água chorosa seus troféus de erva e a ela própria.

(SHAKESPEARE, s.d.)

O primeiro a divulgar o poema no Brasil foi o escritor Rubem Braga, no jornal O pasquim, em 1974, que o escolheu para ensinar "um bocado de poesia" a seus leitores (BRAGA, 1974). 
Mesmo levando-se em conta o fato de tratar-se de uma tradução, a semelhança, neste caso, é mais de assunto do que de estruturação lingüística. Há uma maior liberdade criativa por parte de Antônio Gedeão na construção do seu texto poético, pela própria natureza subjetiva da narração. Com isso, a ligação estrutural, formal, torna-se menos acentuada.

Nesta última estrofe é como se o texto do poeta português quisesse mostrar-se "poético". São marcas dessa intenção de poetizar o texto:

a) o assunto contém a dramaticidade poética, que é a morte de uma jovem, no caso, Ofélia, e tem como ponto de apoio referencial o texto dramático de Shakespeare;

b) o espaço é indeterminado, impreciso: "Foi neste líquido (...) sob um luar gomoso e branco de camélia". Sabe-se, porém, que foi sobre a água, pelo título e pelo contexto do poema;

c) o tempo é igualmente impreciso e indeterminado, indefinido: "numa noite cálida de Verão". Valorizam-se como motivos poéticos os termos noite, adjetivada por cálida reforçada por Verão, para expressar e ressaltar a idéia de calor;

d) a imagem visualiza, aponta o assunto com o tom dramático já referido, num estilo ao gosto dos expressionistas: "apareceu a boiar o cadáver de Ofélia / com um nenúfar na mão";

e) ao contrário da primeira parte do poema em que as palavras queriam mostrar-se denotativas, nesta última parte, os termos se mostram pela sua conotação, polivalência, ambigüidade. Por exemplo, na expressão "luar gomoso", gomoso tanto pode significar "em forma de gomos" como "viscoso, pegajoso" e mesmo, numa interpretação mais livre, "traiçoeiro";

f) reforçando os dois itens anteriores, é de se notar que o vocabulário nesta terceira parte perde a objetividade, a exatidão, a concretude com que se apresentava na primeira parte e passa a constituirse de termos abstratos, subjetivos e com significados, denotativamente, imprecisos: "luar gomoso", "luar branco de camélia", "com um nenúfar na mão";

g) a carga de informatividade textual sobre a personagem Ofélia é, para um discurso que se quisesse referencial, insuficiente. Pelo texto, pouco se saberia sobre ela. As informações nos vêm pela interrelação com outros textos, principalmente, a peça de Shakespeare;

h) do mesmo modo, pode-se referir à diferença quanto a um sujeito que enuncie o que se descreve ou o que se narra. Na primeira parte do poema, tal sujeito era inexistente, mas aparece claramente na segunda parte. Pode-se observar que alguém narra: "Foi neste líquido...".

Com a análise do poema "Lição sobre a água", de Antônio Gedeão, procurou-se exemplificar a profunda ligação entre educação e 
linguagem. Mais especificamente, buscou-se mostrar como um tex to poético pode apresentar "lições", ensinamentos, sem deixar de ser um texto criativo e sem cair em lugares comuns tão freqüentes em muitos autores.

\section{Considerações finais}

A relação entre educação e linguagem é clara, como se viu ao longo deste texto e, pode-se dizer, já pertence ao domínio do saber estabelecido. No ideário de teóricos da educação e de estudiosos da linguagem, essa relação é ressaltada e valonizada como intrínseca e fundamental. Nesse contexto, procurou-se mostrar o aproveitamento que o texto poético faz do tradicionalmente denominado discurso científico como um procedimento, ou seja, um artifício que é também o sentido conferido ao termo procedimento - para se alcançar a própria literariedade, ou, especificamente, a sua condição de poeticidade.

Neste estudo, ao se apresentar a produção de mestrandos do Programa de Pós-Graduação em Educação da PUCPR que trabalharam com a relação entre a educação e a linguagem, buscou-se evidenciar a contribuição que o texto literário, em especial, o poético pode dar à prática pedagógica em diferentes cursos de graduação. É a justificativa para o estudo e para a aplicação do conhecimento produzido sobre os Saberes.

Em particular, sobre o poema enfocado, o que pode ficar de "lição", neste artigo, aproveitando a atmosfera poética do texto de Antônio Gedeão, é que a relação entre educação e linguagem e especificamente entre educação e poesia - ou linguagem poética - pode tornar-se elemento constitutivo da construção e da difusão do conhecimento. Portanto e conseqüentemente, pode contribuir para o ensino e para a aprendizagem em todos os níveis da educação.

\section{Referências}

BAKHTIN, M. V. N. Volochínov. Marxismo e filosofia da linguagem: problemas fundamentais do método sociológico na ciência da linguagem. Tradução de Michel Lahud; et al. 2. ed. São Paulo, SP: Hucitec, 1981.

BARTHES, R. Elementos de semiologia. Tradução de Izidoro Blikstein. 5. ed. São Paulo, SP: Cultrix, 1977. 
BERSTEIN, B. A estruturação do discurso pedagógico: classe, códigos e controle. Tradução de Tomaz Tadeu da Silva e Luís Fernando Gonçalves Pereira. Petrópolis: Vozes, 1996.

BRAGA, R. Lição sobre a água. O Pasquim, Rio de Janeiro, n. 246 p. 26, mar. 1974.

BUENO, J. F. Aspectos da poética de Antônio Gedeão. 1979. Dissertação (Mestrado em Letras) - Pontifícia Universidade Católica do Paraná. Curitiba, 1979.

- Educação, linguagem e produção do conhecimento. Revista Diálogo Educacional, Curitiba, v. 2, n. 4, p. 47-60, jul./dez. 2001.

CAMPOS, M. B. Piaget. Vygotsky e a educação. Disponível em: <http:/ / www.centrorefeducacional.com.br/vygotsky.html>. Acesso em: 26 mar. 2005.

CAMÕ ES. L. Lírica completa: prefácio e notas. Maria de Lourdes Saraiva. Lisboa: Imprensa Nacional, 1980. v. 3.

CHKLOVSKI, V. A arte como procedimento. In: EIKHENBAUM et al. Teoria da literatura: formalistas russos. Tradução de Ana Mariza Ribeiro Filipouski. et al. 2. ed. Porto Alegre: Globo, 1976. p. 39-56.

DIÁLOGO Educacional. Curitiba: Champagnat, 2000-2005.

DUBOIS, J. et al. Dicionário de lingüística. Tradução de Frederico Pessoa de Barros et al. São Paulo, SP: Cultrix, 1978.

ECO, U. Obra aberta: forma e indeterminação nas poéticas contemporâneas. Tradução de Alberto Guzik e Geraldo Gerson de Souza. São Paulo, SP: Perspectiva, 1968.

EIKHENBAUM et al. Teoria da literatura: formalistas russos. Tradução de Ana Mariza Ribeiro Filipouski et al. 2. ed. Porto Alegre: Globo, 1976.

FIORIN, J. L; SAVIOLI, F. P. Para entender o tex to: leitura e redação. 16. ed. São Paulo, SP: Ática, 2002.

GEDEÃO, A. [Rómulo de Carvalho]. A poltrona e outras novelas. Coimbra: Atlântida, 1973. 
. [Rómulo de Carvalho]. Poesias completas: 1956-1967. 5. ed. Lisboa: Portugália, 1975.

[Rómulo de Carvalho]. Breve Cronologia de Rómulo de Carvalho. Disponível em: <http://www.citi.pt/cultura/literatura/poesia/ antonio_gedeao/cronologia.html>. Acesso em: 09 abr. 2005.

GREIMAS, A. J. Semiótica do discurso científico: análise de um texto de Georges Dumézil. In: . Semiótica do discurso científico: da modalidade. Tradução de Cidmar Teodoro Pais. Rio de Janeiro, RJ: Difel, 1976.

JORNAL de Letras. O que era então para si escrever poesia? Lisboa: Artes e Idéias, n. 680, nov. 1996.

LURIA, A. R. Pensamento e linguagem: as últimas conferências de Luria. Tradução de Diana Myriam Lichtenstein e Mário Corso. Porto Alegre: Artes Médicas, 1986.

LY ONS, J. Introdução à lingüística teórica. Tradução de Rosa Virgínia Mattos e outros. São Paulo, SP: Nacional; USP. 1979.

MATTOS, G. Técnicas de redação em língua portuguesa. São Paulo, SP: FTD. [19- ].

MOISÉS, M., (Org.). Literatura portuguesa moderna: guia biográfico, crítico e bibliográfico. São Paulo, SP: Cultrix, 1973.

POZO, J. I. Teorias cognitivas da aprendizagem. Tradução de Juan Acuña Llorens. 3. ed. Reimpressão. Porto Alegre: Artes Médicas, 2002.

RONDAL, J. A. Lenguaje y educación. T raducción de la edición belga (francés) de María Asunción Pujol Amich. Barcelona: Médica, 1980. (Actualidades pedagógicas y psicológicas, 12).

SENA, J. de. A poesia de António Gedeão: esboço de análise objectiva. In: GEDEÃO, A. [Rômulo de Carvalho]. Poesias completas: 1956-1967. 5. ed. Lisboa: Portugália, 1975. p. 11-60.

SHAKESPEARE, W. Hamlet: príncipe da Dinamarca. Tradução de Carlos Alberto Nunes. 2. ed. São Paulo, SP: Melhoramentos, 1956. (Obras completas de Shakespeare, 13). 
UCHÔA, K. C. Construtivismo em Vygotsky. Disponível em: <http:// www.comp.ufla.br/ kacilene/educacao/vygotsky.html>. Acesso em: 26 mar. 2005.

VIGOTSKI, L. S. Pensamento e linguagem. Tradução de Jefferson Luiz Camargo. 2. ed. São Paulo, SP: Martins Fontes, 2003.

WITTGENSTEIN, L. Tractatus logico-philosophicus. Tradução de Luiz Henrique Lopes dos Santos. 2. ed. São Paulo, SP: Edusp, 1994.

Recebido em 04/03/2005. Aprovado em 20/06/2005. 